\title{
Associations between Exposure to Bisphenol A and Behavioral and Cognitive Function in Children with Attention-deficit/Hyperactivity Disorder: A Case-control Study
}

\author{
Seung-Jin Yoo', Hyunjoo $\mathrm{Joo}^{2}$, Dohyun $\mathrm{Kim}^{3}$, Myung Ho Lim ${ }^{1,4}$, Eunjung Kim${ }^{1}$, Mina $\mathrm{Ha}^{2}$, Ho-Jang Kwon ${ }^{1,2}$, \\ Ki Chung Paik ${ }^{1,5}$, Kyoung Min Kim ${ }^{1,5}$ \\ ${ }^{1}$ Environmental Health Center, Dankook University Medical Center, ${ }^{2}$ Department of Preventive Medicine, Dankook University College of \\ Medicine, ${ }^{3}$ Department of Psychiatry, Dankook University Hospital, ${ }^{4}$ Department of Psychology, College of Public Human Resources, Dankook \\ University, ${ }^{5}$ Department of Psychiatry, Dankook University College of Medicine, Cheonan, Korea
}

\begin{abstract}
Objective: Bisphenol A (BPA) is a widely produced synthetic chemical used to manufacture polycarbonate plastics and epoxy resins. We aimed to investigate the association between exposure to BPA and behavioral and cognitive function in children with attention-deficit/hyperactivity disorder (ADHD) and healthy controls.

Methods: The study included 444 children aged from 6 to 10 years. The ADHD and control groups included 195 and 249 children, respectively. BPA levels were assessed via urinalysis, while behavior was assessed using the Korean version of the ADHD Rating Scale (K-ARS) and the Behavior Assessment System for Children (BASC-2). Cognitive function was assessed using the Continuous Performance Test (i.e., ADHD Diagnostic System [ADS]). Participants were categorized into tertile groups based on urinary BPA concentration.

Results: Scores on the K-ARS and the hyperactivity, aggression, anxiety, and depression subscales of the BASC-2 were significantly different among tertile groups for urinary BPA levels. Scores on visual omission error, commission error, response time variability, and auditory commission error of the ADS were significantly different among three BPA groups. Subgroup analysis revealed that these differences of behavior and cognition among three BPA groups were observed in only boys and normal controls.

Conclusion: Exposure to BPA was associated with unfavorable behavioral and cognitive outcomes. Our study extends the findings of previous studies regarding the association between BPA exposure and behavior/cognitive function by including children with ADHD. Further studies are required to determine the mechanisms underlying sex- and group-based differences in these associations.
\end{abstract}

KEY WORDS: Attention deficit-hyperactivity disorder; Bisphenol A; Child behavior; Attention; Toxic environmental substances.

\section{INTRODUCTION}

Attention deficit/hyperactivity disorder (ADHD) is a common neurodevelopmental disorder among children that is characterized by symptoms within the three primary domains of hyperactivity, impulsivity, and inattention [1]. The prevalence of childhood ADHD is approx-

Received: September 10, 2019/ Revised: November 10, 2019

Accepted: November 11, 2019

Address for correspondence: Kyoung Min Kim

Department of Psychiatry, Dankook University College of

Medicine, 119 Dandae-ro, Dongnam-gu, Cheonan 31116, Korea

E-mail: profuture@naver.com

ORCID: https://orcid.org/0000-0003-0577-0701 imately $5 \%$. Although the severity of ADHD symptoms generally decreases with age [2], some residual symptoms may persist, causing functional impairments such as decreased occupational productivity and addiction in adulthood [3-5].

Previous studies have identified sex-based differences in the prevalence and symptoms of ADHD. In community and clinical samples, the male-to-female ratios for ADHD prevalence are 3:1 and 9:1, respectively [6,7]. Furthermore, boys with ADHD are more likely to exhibit externalizing symptoms such as hyperactivity and impulsivity, while girls with ADHD are more likely to exhibit internalizing symptoms such as inattention and anxiety $[6,8]$.

(ㄷ) This is an Open-Access article distributed under the terms of the Creative Commons Attribution Non-Commercial License (http://creativecommons.org/licenses/by-nc/4.0) which permits unrestricted non-commercial use, distribution, and reproduction in any medium, provided the original work is properly cited. 
Although ADHD is a highly heritable disorder, with an estimated heritability rate of 0.76 [9], the disorder is multifactorial in nature and may be heavily influenced by geneenvironment interactions [10]. Research has indicated that exposures to various bioactive chemicals such as polychlorinated biphenyls, lead, cadmium, arsenic, smoking, alcohol, organochloride pesticides, phthalate, and bisphenol A (BPA) are associated with ADHD [11-14]. Whereas heavy metals, organochlorine compounds and currently used pesticides are reported to have strong evidence for the association with neurodevelopment, the evidences for the association of BPA and phthalate with neurodevelopment are yet insufficient with substantial inconsistencies [12].

BPA, an essential component of polycarbonate plastics and epoxy resins, is produced in excess of 8 billion pounds per year [15]. Humans are widely exposed to BPA via numerous consumer products including toys, water pipes, water bottles, food containers, receipt papers, medical devices, dental sealant, and films [16,17].

BPA is an endocrine-disrupting compound with weak estrogenic properties and potential reproductive and neurodevelopmental effects [18]. Previous studies have reported that exposure to BPA is associated with unfavorable behavioral outcomes in children [19]. For example, several studies have revealed that prenatal BPA exposure is associated with higher levels of internalizing symptoms such as anxiety, depression, and withdrawal and externalizing symptoms such as hyperactivity and lower emotional control/inhibition in girls [20-22]. In addition, prenatal BPA exposure has been associated with higher levels of internalizing and externalizing symptoms such as emotional reactivity and aggressive behavior in boys $[16,22,23]$.

In contrast, some studies have reported that BPA exposure is not significantly associated with scores on the Social Responsiveness Scale-a quantitative measure of autistic traits $[24,25]$. Another study investigating the associations between BPA exposure and sustained attention/inhibitory control using the Continuous Performance Test (CPT) did not observe any significant associations between CPT scores and BPA exposure [16].

Although many previous studies have demonstrated that BPA exposure is associated with generally unfavorable outcomes, others have failed to identify such associations [26]. Furthermore, relatively few studies have investigated the associations between BPA exposure and cognitive function. Thus, in the present case-control study, we aimed to investigate the associations between BPA exposure and behavioral/cognitive characteristics in Korean elementary school children with ADHD.

\section{METHODS}

\section{Participants}

Data for the present study were obtained via screenings for neurodevelopmental disorders performed in a medium-sized Korean city between 2008 and 2010. A total of 444 children aged 6 to 10 years were invited to the hospital for diagnostic interviews with a psychiatrist. Among these participants, 195 were diagnosed with ADHD, while 249 were healthy controls. All children and their parents or guardians were provided with a complete explanation of the study, and written informed consent was obtained prior to study entry. The study protocol was approved by the institutional review board (IRB) of Dankook University Hospital (IRB no. 0801-006).

\section{Assessments}

\section{Urinary BPA}

Urinary BPA concentrations were measured via highperformance liquid chromatography-isotope dilution tandem mass spectrometry (Agilent 6410 triple Quad LC/MS; Agilent Technologies, Santa Clara, CA, USA).

\section{Behavioral and cognitive function}

Behavioral characteristics were assessed using the Korean version of the ADHD Rating Scale (K-ARS) and the Behavior Assessment System for Children, Second Edition (BASC-2). The K-ARS is an 18-item checklist designed to assess the severity of ADHD symptoms. Responses on the $\mathrm{K}$-ARS are rated along a 4-point Likert scale $(0=$ never or rarely, $1=$ sometimes, 2 = often, and 4 = very often) [27]. The nine odd-numbered items assess hyperactivity/impulsivity, while the nine even-numbered items assess inattentiveness. The BASC-2 is a 160-item assessment used to investigate internalizing and externalizing symptoms in children across multiple domains. Responses on the BASC-2 are also rated along a 4-point Likert scale (0 = never, 1 = sometimes, 2 = often, and 3 = almost always) [28]. Cognitive function was assessed using the Korean 
version of the computer-based CPT [29], which is known as the ADHD Diagnostic System (ADS). The ADS includes visual and auditory components. The omission error subscale reflects sustained attention, while the commission error subscale reflects inhibitory control. Higher ADS scores are indicative of poorer performance. BASC-2 and ADS scores were converted to standardized T scores $($ mean $=50$, standard deviation $=10)$.

\section{Statistical Analysis}

All participants were categorized into tertiles based on urinary BPA concentration (Q1 = lowest, Q3 = highest). Behavioral (K-ARS and BASC-2) and cognitive function (ADS) scores were compared among the three groups using analyses of variance. Logistic regression analyses were performed to determine odds ratios for ADHD based on urinary BPA levels. In these analyses, sex, age, parental education, household income, and exposure to secondhand smoke were used as covariates. Statistical analyses were conducted using the software package SPSS 25.0 for Windows (IBM Co., Armonk, NY, USA).

\section{RESULTS}

\section{Participant Characteristics}

The characteristics of the included participants are shown in Table 1. The ADHD and control groups exhibited significant differences in parental education level, household income level, and current exposure to secondhand smoke. Urinary BPA levels were significantly higher in the ADHD group than in the control group (Table 2).

\section{Behavioral Characteristics among the BPA Tertiles}

Behavioral characteristics were compared among the three BPA groups (Table 3). K-ARS subscale scores significantly differed among the three groups; specifically, scores were the lowest in the lowest tertile (Q1) and the highest in the highest tertile (Q3). Scores on the hyperactivity, aggression, anxiety, depression, functional communication, externalizing symptoms, and internalizing symptoms subscales and the overall behavioral symptom index of the BASC-2 significantly differed among the three groups.

Table 1. Demographic characteristics of the participants

\begin{tabular}{|c|c|c|c|c|c|}
\hline \multicolumn{2}{|c|}{ Demographic variables } & \multirow{2}{*}{$\frac{\text { Control }}{249}$} & \multirow{2}{*}{$\frac{\text { ADHD }}{195}$} & \multirow[t]{2}{*}{ F or $\chi^{2}$} & \multirow[t]{2}{*}{$p$ value } \\
\hline Number of participants & & & & & \\
\hline Age (yr) & & $8.06 \pm 0.93$ & $7.81 \pm 0.96$ & 2.81 & $0.005^{* *}$ \\
\hline \multirow[t]{2}{*}{ Sex } & Male & $159(63.9)$ & $137(70.3)$ & 2.02 & 0.156 \\
\hline & Female & $90(36.1)$ & $58(29.7)$ & & \\
\hline \multirow[t]{2}{*}{ Paternal educational level } & $\leq 12$ years & $86(34.5)$ & $99(51.0)$ & 12.20 & $<0.000^{* *}$ \\
\hline & $>12$ years & $163(65.5)$ & $95(49.0)$ & & \\
\hline \multirow[t]{2}{*}{ Maternal educational level } & $\leq 12$ years & $120(48.2)$ & $116(59.8)$ & 5.90 & $0.015^{*}$ \\
\hline & $>12$ years & $129(51.8)$ & $78(40.2)$ & & \\
\hline \multirow{3}{*}{$\begin{array}{l}\text { Household income } \\
(1,000 \mathrm{KRW} \text { per month) }\end{array}$} & $\leq 3,000$ & $93(37.5)$ & $100(52.9)$ & 12.70 & $0.002^{* *}$ \\
\hline & $3,000-4,000$ & $86(34.7)$ & $40(21.2)$ & & \\
\hline & $>4,000$ & $69(27.8)$ & $49(25.9)$ & & \\
\hline \multirow[t]{2}{*}{ Exposure to secondhand smoke } & No & $169(69.8)$ & $98(52.1)$ & 14.09 & $<0.000^{* *}$ \\
\hline & Yes & $73(30.2)$ & $90(47.9)$ & & \\
\hline
\end{tabular}

Values are presented as mean \pm standard deviation or number (\%). ADHD, attention deficit/hyperactivity disorder; KRW, Korean won. ${ }^{*} p<0.05 ;{ }^{* *} p<0.01$.

Table 2. Distribution of urinary BPA

\begin{tabular}{lccccccccc}
\hline \multicolumn{1}{c}{ Urinary BPA } & Number & Min & $25 \%$ & Median & $75 \%$ & Max & Mean $(95 \%$ Cl) & SD \\
\hline Control (ppb) & 249 & 0.110 & 0.685 & 1.269 & 2.370 & 32.390 & $2.050(1.691-2.409)$ & 2.875 & 1.273 \\
Case (ppb) & 195 & 0.110 & 0.865 & 1.416 & 2.862 & 46.929 & $2.835(2.115-3.556)$ & 5.101 & 1.587 \\
Control (ppb creatinine) & 249 & 0.110 & 0.790 & 1.330 & 2.426 & 17.370 & $2.105(1.784-2.425)$ & 2.564 & 1.369 \\
Case (ppb creatinine) & 195 & 0.110 & 1.012 & 1.790 & 3.100 & 38.590 & $2.990(2.374-3.606)$ & 4.361 & 1.848 \\
\hline
\end{tabular}

BPA, bisphenol A; Cl, confidence interval; SD, standard deviation; GM, geometric mean; ppb, parts per billion. 
Table 3. Behavioral characteristics of tertile groups according to the urinary bisphenol A concentration

\begin{tabular}{|c|c|c|c|c|c|}
\hline Tertile group of urine bisphenol A & Q1 ( $n=148)$ & Q2 $(n=147)$ & Q3 $(n=149)$ & $\mathrm{F}$ & $p$ value \\
\hline \multicolumn{6}{|l|}{ K-ARS } \\
\hline Total & $11.8 \pm 12.1$ & $15.2 \pm 11.9$ & $17.4 \pm 11.6$ & 8.44 & $<0.000^{* *}$ \\
\hline Hyperactivity-Impulsivity & $5.0 \pm 5.5$ & $6.8 \pm 5.9$ & $7.6 \pm 5.9$ & 8.34 & $<0.000^{* *}$ \\
\hline Inattention & $6.9 \pm 6.9$ & $8.4 \pm 6.5$ & $9.8 \pm 6.4$ & 7.32 & $0.001^{* *}$ \\
\hline \multicolumn{6}{|l|}{ BASC-2 } \\
\hline Hyperactivity & $47.8 \pm 10.2$ & $50.6 \pm 11.5$ & $51.5 \pm 11.0$ & 4.54 & $0.011^{*}$ \\
\hline Aggression & $46.8 \pm 8.0$ & $49.0 \pm 9.5$ & $49.3 \pm 8.3$ & 3.65 & $0.027^{*}$ \\
\hline Conduct problems & $47.4 \pm 10.0$ & $49.5 \pm 9.9$ & $49.5 \pm 9.9$ & 2.07 & 0.127 \\
\hline Anxiety & $41.8 \pm 7.5$ & $43.0 \pm 7.9$ & $44.3 \pm 8.6$ & 3.58 & $0.029 *$ \\
\hline Depression & $47.5 \pm 8.8$ & $49.7 \pm 9.6$ & $51.2 \pm 9.8$ & 5.63 & $0.004^{* *}$ \\
\hline Somatization & $44.5 \pm 9.2$ & $43.7 \pm 8.0$ & $46.1 \pm 9.7$ & 2.62 & 0.074 \\
\hline Atypicality & $48.8 \pm 8.7$ & $50.2 \pm 11.0$ & $51.5 \pm 11.0$ & 2.62 & 0.074 \\
\hline Withdrawal & $48.6 \pm 8.7$ & $50.1 \pm 10.2$ & $50.6 \pm 9.4$ & 1.79 & 0.168 \\
\hline Attention problems & $53.2 \pm 11.0$ & $55.0 \pm 11.2$ & $55.5 \pm 10.0$ & 1.79 & 0.168 \\
\hline Adaptability & $48.3 \pm 8.9$ & $48.2 \pm 9.8$ & $47.7 \pm 9.3$ & 0.16 & 0.854 \\
\hline Social skills & $43.5 \pm 8.6$ & $42.7 \pm 9.6$ & $42.7 \pm 9.0$ & 0.39 & 0.681 \\
\hline Leadership & $44.3 \pm 8.8$ & $44.0 \pm 9.1$ & $44.1 \pm 9.3$ & 0.05 & 0.953 \\
\hline Activities of daily living & $45.9 \pm 10.6$ & $44.6 \pm 10.2$ & $43.3 \pm 11.3$ & 2.12 & 0.121 \\
\hline Functional communication & $49.0 \pm 9.3$ & $46.1 \pm 11.2$ & $44.7 \pm 10.6$ & 6.49 & $0.002^{* *}$ \\
\hline Externalizing problems & $47.0 \pm 9.3$ & $49.7 \pm 10.6$ & $50.1 \pm 9.6$ & 4.16 & $0.016^{*}$ \\
\hline Internalizing problems & $43.3 \pm 8.7$ & $44.4 \pm 8.5$ & $46.6 \pm 10.0$ & 4.79 & $0.009^{* *}$ \\
\hline Behavioral symptom index & $48.4 \pm 9.4$ & $51.0 \pm 10.5$ & $52.0 \pm 9.9$ & 5.18 & $0.006^{* *}$ \\
\hline Adaptive skills & $45.5 \pm 8.4$ & $44.3 \pm 9.7$ & $43.6 \pm 9.4$ & 1.67 & 0.189 \\
\hline
\end{tabular}

Values are presented as mean \pm standard deviation.

K-ARS, Korean version of the Attention Deficit/Hyperactivity Disorder Rating Scale; BASC-2, Behavior Assessment System for Children, Second Edition.

${ }^{*} p<0.05 ;{ }^{* *} p<0.01$.

However, significant differences in behavioral characteristics were observed between boys and girls. When analyses were restricted to girls, no significant differences in the K-ARS or BASC-2 subscale scores were identified among the tertiles (Supplementary Tables 1, 2; available online).

Also, significant differences in the associations between behavioral characteristics and urinary bisphenol A were observed between normal control and ADHD groups (Table 5) (Supplementary Tables 3, 4; available online). The scores on K-ARS and BASC-2 subscales including hyperactivity, aggression, conduct problem, anxiety, depression, externalizing problems, and internalizing disorder were significantly different among the tertile groups in control group. However, no significant differences of scores on any subscales of K-ARS and BASC-2 among tertile groups were observed in ADHD groups.

\section{Cognitive Function among the BPA Tertiles}

Significant differences in visual omission error, commission error, and response time variability, and in audi- tory commission error scores were observed among the three BPA groups (Table 4).

We also observed significant differences in cognitive function between boys and girls (Supplementary Tables 1 , 2; available online). Although boys exhibited significant differences in ADS scores based on BPA group, no such differences were observed among girls for any ADS subscale. The subgroup analysis for control and ADHD groups showed no significant differences in ADS subscales among three BPA groups other than the auditory omission error in control (Table 5) (Supplementary Table 3; available online) and visual commission error in ADHD group (Supplementary Table 4; available online).

\section{Odds Ratios for ADHD among the BPA Tertile Groups}

Similar to the results for behavior and cognitive function, odds ratios for ADHD significantly differed according to sex (Table 6). Boys with higher urinary BPA levels exhibited significantly higher odds ratios for ADHD. When analyses were restricted to girls, no significant dif- 
Table 4. Cognitive characteristics of tertile groups according to the urinary bisphenol A concentration

\begin{tabular}{llllll}
\hline Tertile group of urine bisphenol A & Q1 $(n=146)$ & Q2 $(n=147)$ & Q3 $(n=145)$ & $\mathrm{F}$ & $p$ value \\
\hline ADS & & & & \\
$\quad$ Visual omission error & $56.9 \pm 20.8$ & $59.3 \pm 22.8$ & $64.7 \pm 32.1$ & 3.52 & $0.030^{*}$ \\
$\quad$ Visual commission error & $56.6 \pm 21.4$ & $57.5 \pm 19.3$ & $65.2 \pm 26.9$ & 6.23 & $0.002^{* *}$ \\
$\quad$ Visual response time & $50.8 \pm 12.9$ & $51.2 \pm 12.0$ & $51.4 \pm 14.6$ & 0.08 & 0.925 \\
$\quad$ Visual response time variability & $58.2 \pm 18.5$ & $61.1 \pm 21.7$ & $64.8 \pm 26.6$ & 3.08 & $0.047^{*}$ \\
Auditory omission error & $51.5 \pm 12.0$ & $51.7 \pm 14.9$ & $53.1 \pm 17.2$ & 0.53 & 0.588 \\
$\quad$ Auditory commission error & $48.5 \pm 11.1$ & $48.8 \pm 14.1$ & $53.3 \pm 20.7$ & 4.07 & $0.018^{*}$ \\
Auditory response time & $58.0 \pm 16.6$ & $58.1 \pm 14.9$ & $55.8 \pm 17.2$ & 0.91 & 0.404 \\
Auditory response time variability & $55.2 \pm 14.0$ & $57.2 \pm 14.4$ & $58.5 \pm 14.1$ & 1.98 & 0.139 \\
\hline
\end{tabular}

Values are presented as mean \pm standard deviation.

ADS, Attention Deficit/Hyperactivity Disorder Diagnostic System.

${ }^{*} p<0.05 ;{ }^{* *} p<0.01$.

Table 5. Behavioral and cognitive characteristics according to urinary bisphenol A concentration in subgroups of control and ADHD

\begin{tabular}{|c|c|c|c|c|c|c|c|c|c|c|}
\hline \multirow{2}{*}{$\begin{array}{c}\text { Tertile group of } \\
\text { urine bisphenol A }\end{array}$} & \multicolumn{5}{|c|}{ Control } & \multicolumn{5}{|c|}{ ADHD } \\
\hline & Q1 $(n=93)$ & Q2 $(n=82)$ & Q3 $(n=74)$ & $\mathrm{F}$ & $p$ value & $\mathrm{Q} 1(\mathrm{n}=55)$ & Q2 $(n=65)$ & Q3 (n = 75) & $\mathrm{F}$ & $p$ value \\
\hline \multicolumn{11}{|l|}{ K-ARS } \\
\hline Total & $5.4 \pm 8.6$ & $8.1 \pm 8.7$ & $9.9 \pm 9.4$ & 5.41 & $0.005^{* *}$ & $22.7 \pm 8.9$ & $24.2 \pm 8.8$ & $24.9 \pm 8.3$ & 1.06 & 0.348 \\
\hline Hyperactivity-Impulsivity & $2.1 \pm 3.9$ & $3.5 \pm 4.4$ & $4.1 \pm 4.6$ & 4.62 & $0.011^{*}$ & $9.7 \pm 4.5$ & $11.0 \pm 4.8$ & $11.1 \pm 4.9$ & 1.59 & 0.206 \\
\hline Inattention & $3.3 \pm 5.0$ & $4.6 \pm 4.7$ & $5.8 \pm 5.3$ & 5.35 & $0.005^{* *}$ & $12.9 \pm 5.3$ & $13.2 \pm 5.1$ & $13.7 \pm 4.8$ & 0.43 & 0.652 \\
\hline \multicolumn{11}{|l|}{ BASC-2 } \\
\hline Externalizing problems & $42.8 \pm 5.8$ & $45.3 \pm 9.0$ & $46.8 \pm 9.0$ & 5.27 & $0.006^{* *}$ & $54.1 \pm 9.8$ & $55.1 \pm 9.9$ & $53.5 \pm 9.0$ & 0.50 & 0.604 \\
\hline Internalizing problems & $40.9 \pm 7.0$ & $43.0 \pm 7.9$ & $45.0 \pm 10.4$ & 4.70 & $0.010^{*}$ & $47.3 \pm 9.7$ & $46.1 \pm 8.9$ & $48.2 \pm 9.4$ & 0.89 & 0.412 \\
\hline Behavioral symptom index & $44.5 \pm 7.0$ & $47.1 \pm 9.6$ & $48.3 \pm 9.4$ & 4.18 & $0.016^{*}$ & $54.9 \pm 9.2$ & $55.8 \pm 9.5$ & $55.9 \pm 8.9$ & 0.21 & 0.809 \\
\hline Adaptive skills & $47.9 \pm 7.8$ & $47.3 \pm 9.8$ & $47.1 \pm 9.2$ & 0.17 & 0.846 & $41.7 \pm 8.0$ & $40.5 \pm 8.0$ & $40.1 \pm 8.2$ & 0.65 & 0.521 \\
\hline \multicolumn{11}{|l|}{ ADS } \\
\hline Visual omission error & $51.9 \pm 15.1$ & $53.0 \pm 21.0$ & $52.7 \pm 18.0$ & 0.08 & 0.923 & $65.2 \pm 25.8$ & $67.2 \pm 22.6$ & $76.6 \pm 38.1$ & 2.72 & 0.069 \\
\hline Visual comission error & $50.5 \pm 14.9$ & $51.9 \pm 14.7$ & $54.8 \pm 23.6$ & 1.19 & 0.306 & $66.7 \pm 26.3$ & $64.5 \pm 22.1$ & $75.4 \pm 26.2$ & 3.66 & $0.027^{*}$ \\
\hline Auditory omission error & $48.9 \pm 10.5$ & $45.1 \pm 8.9$ & $46.2 \pm 11.4$ & 3.22 & $0.042^{*}$ & $55.7 \pm 13.1$ & $60.0 \pm 16.8$ & $59.7 \pm 19.1$ & 1.21 & 0.301 \\
\hline Auditory comission error & $45.9 \pm 9.1$ & $44.1 \pm 11.5$ & $46.7 \pm 18.5$ & 0.80 & 0.450 & $52.7 \pm 12.8$ & $54.8 \pm 14.9$ & $59.5 \pm 20.8$ & 2.77 & 0.065 \\
\hline
\end{tabular}

Values are presented as mean \pm standard deviation.

ADHD, attention deficit/hyperactivity disorder; K-ARS, Korean version of the Attention Deficit/Hyperactivity Disorder Rating Scale; BASC-2, Behavior Assessment System for Children, Second Edition; ADS, Attention Deficit/Hyperactivity Disorder Diagnostic System.

${ }^{*} p<0.05 ;{ }^{* *} p<0.01$.

ferences were observed among the tertiles.

\section{DISCUSSION}

In the present study, we investigated the associations between urinary BPA concentration and behavioral and cognitive function in Korean elementary school children with ADHD and healthy controls. Our findings indicated that higher urinary BPA levels were associated with ADHD symptoms that were more severe, as assessed using the K-ARS. Higher urinary BPA levels were also associated with higher scores on the hyperactivity, aggression, anxiety, and depression subscales of the BASC-2. The present findings are consistent with the results of previous studies reporting higher levels of anxiety and depression in children with higher urinary BPA levels $[16,22,30]$. However, our findings are somewhat inconsistent with those of studies reporting that childhood BPA exposure is not significantly associated with behavioral problems assessed using BASC-2 or Childhood Behavior Checklist scores $[21,26]$. However, in these studies, significant associations were observed between prenatal BPA exposure and behavioral symptoms.

In addition, we observed significant differences in the association between urinary BPA levels and behavioral characteristics according to sex. In our study, urinary BPA 
Table 6. OR and 95\% $\mathrm{Cl}$ of ADHD associated with urinary BPA level

\begin{tabular}{|c|c|c|c|c|c|c|c|c|}
\hline \multirow{2}{*}{$\begin{array}{c}\text { Tertile groups of urine } \\
\text { BPA level }\end{array}$} & \multirow{2}{*}{ Number } & \multirow{2}{*}{$\begin{array}{l}\text { Number of } \\
\text { cases (\%) }\end{array}$} & \multicolumn{2}{|c|}{ 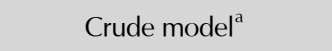 } & \multicolumn{2}{|c|}{ Adjusted model $1^{\mathrm{b}}$} & \multicolumn{2}{|c|}{ Adjusted model $2^{c}$} \\
\hline & & & OR & $95 \% \mathrm{Cl}$ & OR & $95 \% \mathrm{Cl}$ & OR & $95 \% \mathrm{Cl}$ \\
\hline \multicolumn{9}{|l|}{ All } \\
\hline \multicolumn{9}{|c|}{ Urinary BPA level (min, max) (ppb) } \\
\hline Q1 $(0.11,0.93)$ & 148 & $55(37.2)$ & 1 & Reference & 1 & Reference & 1 & Reference \\
\hline Q2 $(0.95,2.01)$ & 147 & $65(44.2)$ & 1.340 & $0.841-2.136$ & 1.283 & $0.784-2.099$ & 1.236 & $0.744-2.053$ \\
\hline Q3 $(2.05,46.93)$ & 149 & $75(50.3)$ & $1.714^{*}$ & $1.079-2.723$ & 1.413 & $0.850-2.348$ & 1.404 & $0.833-2.365$ \\
\hline \multicolumn{9}{|l|}{ Boys } \\
\hline \multicolumn{9}{|c|}{ Urinary BPA level (min, max) (ppb) } \\
\hline Q1 $(0.11,0.93)$ & 101 & $33(32.7)$ & 1 & Reference & 1 & Reference & 1 & Reference \\
\hline Q2 $(0.95,2.01)$ & 97 & $48(49.5)$ & $2.019 *$ & $1.135-3.589$ & $1.878^{*}$ & $1.040-3.392$ & 1.808 & $0.985-3.318$ \\
\hline Q3 $(2.05,46.93)$ & 98 & $56(57.1)$ & $2.747^{* *}$ & $1.543-4.893$ & $2.216^{*}$ & $1.199-4.094$ & $2.219 *$ & $1.131-4.006$ \\
\hline \multicolumn{9}{|l|}{ Girls } \\
\hline \multicolumn{9}{|c|}{ Urinary BPA level (min, max) (ppb) } \\
\hline Q1 $(0.11,0.93)$ & 47 & $22(46.8)$ & 1 & Reference & 1 & Reference & 1 & Reference \\
\hline Q2 $(0.95,2.01)$ & 50 & $17(34.0)$ & 0.585 & $0.258-1.328$ & 0.549 & $0.203-1.484$ & 0.498 & $0.174-1.421$ \\
\hline Q3 $(2.05,46.93)$ & 51 & $19(37.3)$ & 0.675 & $0.301-1.511$ & 0.483 & $0.176-1.323$ & 0.480 & $0.170-1.360$ \\
\hline
\end{tabular}

OR, odds ratio; $\mathrm{Cl}$, confidence interval; $\mathrm{ADHD}$, attention deficit hyperactivity disorder; BPA, bisphenol A.

${ }^{a} \mathrm{OR}$ and $95 \% \mathrm{Cl}$ estimated using logistic regression model referenced by the first quartile group of urinary $\mathrm{BPA}$ level. ${ }^{\mathrm{b}} \mathrm{OR}$ and $95 \% \mathrm{Cl}$ estimated using logistic regression model referenced by the first quartile group of urinary BPA level adjusted for age, sex, paternal and maternal educational level, and household income level. ' $\mathrm{OR}$ and $95 \% \mathrm{Cl}$ estimated using logistic regression model referenced by the first quartile group of urinary BPA level adjusted for age, sex, paternal and maternal educational level, household income level, and current exposure to secondhand smoke.

${ }^{*} p<0.05 ; * * p<0.01$.

levels were associated with hyperactivity, conduct problems, anxiety, and depression in boys. However, there were no significant associations between BPA levels and scores on any subscales of the K-ARS or BASC-2 in girls. No previous studies have reported such sex-based differences, although some have identified significant associations between childhood BPA exposure and behavioral problems in both sexes [19].

In contrast to previous studies on childhood BPA exposure, studies on prenatal BPA levels have noted different sex-based findings. While some studies reported that higher levels of prenatal BPA exposure are associated with internalizing/externalizing symptoms that are more severe in boys $[16,23,26]$. Other studies have demonstrated that prenatal exposure is significantly associated with increases in anxiety, depression, hyperactivity, or inattention in girls, which is inconsistent with our findings [20-22].

We observed similar results for odds ratios for ADHD based on urinary BPA levels. Overall, odds ratios for ADHD were higher in groups with relatively higher BPA levels. However, in the subgroup analysis, significant positive associations between odds ratios for ADHD and BPA levels were observed in boys only. This finding is con- sistent with those of a previous study, which reported that prenatal BPA exposure is associated with an increased risk of ADHD-hyperactivity symptoms in boys at age 4 and an increased risk of ADHD-inattention symptoms in boys only [18].

In our study, the associations between the behavioral problems and urinary BPA level were significantly different between normal controls and ADHD groups. These are very impressive findings, considering that most of the previous studies of associations between children's behavior and BPA exposure were conducted with samples based on the general population and did not consider the children with ADHD separately [21-24,26,30]. Our study showed that BPA exposure was significantly associated with behavioral problems in the control group, which suggests that BPA exposure might also negatively impact children's behavior at the subclinical level. Rather, the ADHD group did not show significant differences in behavioral problems among the three BPA groups. These findings suggest that the negative behavioral problems associated with BPA exposure could be masked by the symptoms of ADHD per se because ADHD is a major contributor to the behavioral problems. The findings of our present study are novel. Future prospective studies in- 
cluding the children with ADHD are warranted to confirm these findings.

Our analysis of ADS scores revealed that cognitive function was also associated with BPA levels. Higher omission and commission error scores on the ADS are indicative of greater impairments in sustained attention and inhibitory control, respectively. The highest scores on these domains were observed in the highest BPA tertile, indicating that BPA exposure exhibits a significant negative association with cognitive performance. However, this finding is in contrast to those of a previous study, which did not identify significant associations between BPA exposure and scores on the CPT [16]. Notably, the significant associations between BPA levels and cognitive function in the present study were observed in boys only.

Estrogen is a crucial hormone for the structural and functional organization of the brain during fetal development [31]. BPA is known to act as a weak estrogen agonist, which may affect brain development [32]. Several animal studies have revealed that prenatal exposure to BPA can affect brain structure and alter levels of sexual and social behavior, aggression, hyperactivity, anxiety, and novelty seeking [18,31]. As ADHD is a neurodevelopmental disorder that is influenced by multiple environmental factors, our results suggest that BPA exposure during childhood influences the incidence of ADHD as well as symptom presentation.

According to the theory of sexual differentiation [31], exposure to estrogen agonists including BPA during the critical developmental period should exert a larger effect in girls than in boys. However, the sex-specific mechanisms underlying the effects of BPA on neurodevelopment remain uncertain [18], and the discrepancies observed between our results and those of previous studies remain to be resolved. Several possible explanations for these discrepancies exist. First, various studies have reported positive associations between prenatal BPA exposure and behavior in boys $[16,23,26]$. Although we did not assess prenatal BPA exposure in the present study, it is possible that children were continuously exposed to higher BPA levels throughout the developmental period. Second, in contrast to previous studies, we utilized a case-control design, including both ADHD and healthy control groups. Research has revealed that ADHD is more prevalent in boys, and that boys with ADHD tend to be more hyperactive than are girls $[6,8]$. Thus, in our study, boys with
ADHD may have engaged in more activities associated with BPA exposure (i.e., drinking canned beverages or playing with plastic toys). Finally, ADHD is a multifactorial disorder that is heavily influenced by genetic factors [33], and ethnic differences in genetic factors among participants in these studies may explain the observed discrepancies. For instance, the prevalence of the dopamine D4 receptor 7-repeat allele, which is associated with the occurrence of $\mathrm{ADHD}$, is much lower in Asian populations than it is in Western populations [34,35]. Thus, further cross-cultural studies including patients with $\mathrm{ADHD}$ are required to explain why the associations between BPA and behavioral characteristics among girls in our study differed from those observed in previous studies.

\section{Limitations}

The present study possesses some limitations of note, including its cross-sectional design, which limited our ability to explore the causal relationship between BPA exposure and ADHD symptoms. Children with ADHD are more hyperactive and may be more frequently exposed to BPA via toys or disposable food containers made with plastic. To overcome this limitation, further longitudinal or quasi-experimental studies are required. In addition, previous studies for the association between BPA exposure and children's behavior have reported differential associations with children's behavior of the prenatal and childhood exposure to BPA [19]. Thus, the longitudinal study including the regular assessments of BPA exposure from prenatal period to childhood is warranted to confirm the present findings. The second limitation of our study might be caused by the half-life of BPA in humans. Previous studies have stated that the half-life of BPA is less than 6 hours [36,37], and this short half-life may have resulted in bias based on the gap between exposure and assessment. Repeated assessments are required in order to evaluate exposure more precisely. However, another population-based study reported that the half-life of BPA is much longer than expected, based on acute exposure experiments [38]. In future, quasi-experimental studies may help to overcome this limitation and determine the precise effects of BPA exposure.

Despite the aforementioned limitations, our research extends the findings of previous studies regarding the association between BPA exposure and behavioral/cognitive 
function by including children with ADHD. Our results indicated that childhood BPA exposure is associated with an increased risk of ADHD and unfavorable behavioral and cognitive outcomes in boys. However, no such associations were observed in girls.

\section{Acknowledgments}

This study was funded by the Ministry of Environment, Republic of Korea. The funding source had no role in the design of study, data collection, data analysis, and preparation of the manuscript.

\section{Conflicts of Interest}

No potential conflict of interest relevant to this article was reported.

\section{Author Contributions}

Conceptualization: Kyoung Min Kim, Ki Chung Paik, Mina Ha, Ho-Jang Kwon, Myung Ho Lim. Data acquisition: Seung-Jin Yoo, Eunjung Kim, Mina Ha, Ho-Jang Kwon, Ki Chung Paik. Formal analysis: Seung-Jin Yoo, Hyunjoo Joo, Kyoung Min Kim. Draft writing: Seung-Jin Yoo, Hyunjoo Joo, Kyoung Min Kim. Review and editting: Dohyun Kim, Myung Ho Lim, Kyoung Min Kim.

\section{ORCID}

Seung-Jin Yoo

Hyunjoo Joo

Dohyun Kim

Myung Ho Lim

Eunjung Kim

Mina $\mathrm{Ha}$

Ho-Jang Kwon

Ki Chung Paik

https://orcid.org/0000-0002-0643-5609 https://orcid.org/0000-0002-2791-158X https://orcid.org/0000-0002-6069-2032 https://orcid.org/0000-0001-5370-4376 https://orcid.org/0000-0002-3285-6968 https://orcid.org/0000-0003-1011-9446 https://orcid.org/0000-0003-3029-5674 Kyoung Min Kim https://orcid.org/0000-0003-0465-8371 https://orcid.org/0000-0003-0577-0701

\section{REFERENCES}

1. American Psychiatric Association. Diagnostic and statistical manual of mental disorders: DSM-5. 5th ed. Washington, D.C.:American Psychiatric Association;2013.

2. Faraone SV, Biederman J, Mick E. The age-dependent decline of attention deficit hyperactivity disorder: a meta-analysis of follow-up studies. Psychol Med 2006;36:159-65.

3. Biederman J, Mick E, Faraone SV. Age-dependent decline of symptoms of attention deficit hyperactivity disorder: impact of remission definition and symptom type. Am J Psychiatry 2000;157:816-818.
4. Gjervan B, Torgersen T, Nordahl HM, Rasmussen K. Functional impairment and occupational outcome in adults with $A D H D$. I Atten Disord 2012;16:544-552.

5. Kessler RC, Adler L, Barkley R, Biederman J, Conners CK, Demler $\mathrm{O}$, et al. The prevalence and correlates of adult $A D H D$ in the United States: results from the National Comorbidity Survey Replication. Am J Psychiatry 2006;163: 716-723.

6. American Psychiatric Association. Diagnostic and statistical manual of mental disorders: DSM-IV-TR ${ }^{\mathbb{R}}$. 4th ed. Washington, D.C.:American Psychiatric Association;2000.

7. Willcutt EG. The prevalence of DSM-IV attention-deficit/hyperactivity disorder: a meta-analytic review. Neurotherapeutics 2012;9:490-499.

8. Gershon J. A meta-analytic review of gender differences in ADHD. J Atten Disord 2002;5:143-154.

9. Faraone SV, Perlis RH, Doyle AE, Smoller JW, Goralnick JJ, Holmgren MA, et al. Molecular genetics of attention-deficit/hyperactivity disorder. Biol Psychiatry 2005;57:1313-1323.

10. Becker K, El-Faddagh M, Schmidt MH, Esser G, Laucht M. Interaction of dopamine transporter genotype with prenatal smoke exposure on ADHD symptoms. J Pediatr 2008;152: 263-269.

11. Banerjee TD, Middleton F, Faraone SV. Environmental risk factors for attention-deficit hyperactivity disorder. Acta Paediatr 2007;96:1269-1274.

12. Vrijheid M, Casas M, Gascon M, Valvi D, Nieuwenhuijsen M. Environmental pollutants and child health-a review of recent concerns. Int J Hyg Environ Health 2016;219:331-342.

13. Nigg JT, Knottnerus GM, Martel MM, Nikolas M, Cavanagh K, Karmaus W, et al. Low blood lead levels associated with clinically diagnosed attention-deficit/hyperactivity disorder and mediated by weak cognitive control. Biol Psychiatry 2008;63: 325-331.

14. Polańska K, Jurewicz J, Hanke W. Review of current evidence on the impact of pesticides, polychlorinated biphenyls and selected metals on attention deficit/hyperactivity disorder in children. Int J Occup Med Environ Health 2013;26:16-38.

15. Vandenberg LN, Chahoud I, Heindel JJ, Padmanabhan V, Paumgartten FJ, Schoenfelder G. Urinary, circulating, and tissue biomonitoring studies indicate widespread exposure to bisphenol A. Environ Health Perspect 2010;118:1055-1070.

16. Harley KG, Gunier RB, Kogut K, Johnson C, Bradman A, Calafat AM, et al. Prenatal and early childhood bisphenol $A$ concentrations and behavior in school-aged children. Environ Res 2013;126:43-50.

17. Vandenberg LN, Hauser R, Marcus M, Olea N, Welshons WV. Human exposure to bisphenol A (BPA). Reprod Toxicol 2007; 24:139-177

18. Casas M, Forns J, Martínez D, Avella-García C, Valvi D, Ballesteros-Gómez A, et al. Exposure to bisphenol A during pregnancy and child neuropsychological development in the INMA-Sabadell cohort. Environ Res 2015;142:671-679. 
19. Ejaredar M, Lee Y, Roberts DJ, Sauve R, Dewey D. Bisphenol A exposure and children's behavior: a systematic review. J Expo Sci Environ Epidemiol 2017;27:175-183.

20. Braun JM, Yolton K, Dietrich KN, Hornung R, Ye X, Calafat AM, et al. Prenatal bisphenol A exposure and early childhood behavior. Environ Health Perspect 2009;117:1945-1952.

21. Braun JM, Kalkbrenner AE, Calafat AM, Yolton K, Ye X, Dietrich KN, et al. Impact of early-life bisphenol A exposure on behavior and executive function in children. Pediatrics 2011;128:873-882.

22. Roen EL, Wang Y, Calafat AM, Wang S, Margolis A, Herbstman J, et al. Bisphenol $A$ exposure and behavioral problems among inner city children at 7-9 years of age. Environ Res 2015;142:739-745.

23. Evans SF, Kobrosly RW, Barrett ES, Thurston SW, Calafat AM, Weiss B, et al. Prenatal bisphenol A exposure and maternally reported behavior in boys and girls. Neurotoxicology 2014; 45:91-99.

24. Braun JM, Kalkbrenner AE, Just AC, Yolton K, Calafat AM, Sjödin A, et al. Gestational exposure to endocrine-disrupting chemicals and reciprocal social, repetitive, and stereotypic behaviors in 4- and 5-year-old children: the HOME study. Environ Health Perspect 2014;122:513-520.

25. Miodovnik A, Engel SM, Zhu C, Ye X, Soorya LV, Silva MJ, et al. Endocrine disruptors and childhood social impairment. Neurotoxicology 2011;32:261-267.

26. Perera F, Vishnevetsky J, Herbstman JB, Calafat AM, Xiong W, Rauh $\mathrm{V}$, et al. Prenatal bisphenol a exposure and child behavior in an inner-city cohort. Environ Health Perspect 2012;120: 1190-1194.

27. DuPaul GJ, Anastopoulos AD, Power TJ, Reid R, Ikeda MJ, McGoey KE. Parent ratings of attention-deficit/hyperactivity disorder symptoms: factor structure and normative data. J Psychopathol Behav Assess 1998;20:83-102.

28. Reynolds CR. Behavior assessment system for children. In: Weiner IB, Craighead WE, editors. The Corsini encyclopedia of psychology. 4th ed. Hoboken:Wiley;2010.
29. Greenberg LM, Waldman ID. Developmental normative data on the test of variables of attention (T.O. V.A.). J Child Psychol Psychiatry 1993;34:1019-1030.

30. Hong SB, Hong YC, Kim JW, Park EJ, Shin MS, Kim BN, et al. Bisphenol $A$ in relation to behavior and learning of school-age children. J Child Psychol Psychiatry 2013;54:890-899.

31. Wolstenholme JT, Rissman EF, Connelly JJ. The role of Bisphenol $A$ in shaping the brain, epigenome and behavior. Horm Behav 2011;59:296-305.

32. Rochester JR. Bisphenol $A$ and human health: a review of the literature. Reprod Toxicol 2013;42:132-155.

33. Thapar A, Langley K, Asherson P, Gill M. Gene-environment interplay in attention-deficit hyperactivity disorder and the importance of a developmental perspective. Br J Psychiatry 2007;190:1-3.

34. Leung PW, Lee CC, Hung SF, Ho TP, Tang CP, Kwong SL, et al. Dopamine receptor D4 (DRD4) gene in Han Chinese children with attention-deficit/hyperactivity disorder (ADHD): increased prevalence of the 2-repeat allele. Am J Med Genet $B$ Neuropsychiatr Genet 2005;133B:54-56.

35. Luk ESL, Leung PWL, Ho TP. Cross-cultural/ethnical aspects of childhood hyperactivity. In: Sandberg S, editor. Hyperactivity and attention disorders of childhood. 2nd ed. Cambridge: Cambridge University Press;2002. p.64-98.

36. Völkel W, Bittner N, Dekant W. Quantitation of bisphenol $A$ and bisphenol $A$ glucuronide in biological samples by high performance liquid chromatography-tandem mass spectrometry. Drug Metab Dispos 2005;33:1748-1757.

37. Völkel W, Colnot T, Csanády GA, Filser JG, Dekant W. Metabolism and kinetics of bisphenol $a$ in humans at low doses following oral administration. Chem Res Toxicol 2002; 15:1281-1287.

38. Stahlhut RW, Welshons WV, Swan SH. Bisphenol A data in NHANES suggest longer than expected half-life, substantial nonfood exposure, or both. Environ Health Perspect 2009; 117:784-789. 